\title{
Spermaturia and puberty
}

Juri L Pedersen, Karsten Nysom, Merete Jørgensen, Claus T Nielsen, Jørn Müller, Niels Keiding, Niels E Skakkebæk

\begin{abstract}
The pattern of spermaturia in boys at different stages of puberty was investigated. Fractionated 24 hour urine was collected for nine consecutive days from eight boys aged 13-14 years and 10 boys aged 15-17 years. Spermatozoa were detected by microscopic examination of the sediment. Sex characteristics were recorded. Fifty five per cent of all urine samples were positive for sperm and all boys showed spermaturia. A large variation in spermaturia was found between and within boys at the same stage of puberty. Spermaturia was a more common and regular event during early and mid-puberty than in more mature subjects. This indicates that the mechanism of spermaturia in early and late puberty could be different. It is suggested that spermaturia in non-virilised boys could be a result of a spontaneous, continuous flow of spermatozoa to the urethra in contrast with the peristaltic flow during ejaculation occurring at a later stage of puberty.

(Arch Dis Child 1993; 69: 384-387)
\end{abstract}

Spermarche has been defined as the first spermaturia, ${ }^{1-4}$ and this event has been considered an important milestone in male puberty. A few longitudinal studies ${ }^{156}$ as well as cross sectional studies ${ }^{2-4}$ have estimated the median age of spermarche to be 13-14 years. Sperm can be detected in the urine of boys after the spermarche. ${ }^{7}$ Sperm negative urine samples occur after the achievement of spermarche, however, and this phenomenon has been considered a 'false negative' observation.

Previous studies have described a few cases of spermaturia in boys at an immature stage of puberty, including examples of completely non-virilised boys with no signs of puberty. ${ }^{6}$ The mechanism of spermaturia in these boys is enigmatic, because studies have shown that spermaturia from adults is the consequence of urethral washing after ejaculations, ${ }^{8}$ and the only two known studies of the onset of ejaculations in puberty showed that boys were generally in middle or late puberty before they experienced their first ejaculations. ${ }^{910}$ These observations seem to indicate that there is a shift in the mechanism of spermaturia from early to late puberty. All previous studies of spermarche have been hampered by the common occurrence of false negative samples. Consequently, the finding of a sperm negative sample does not necessarily mean that spermarche has not been achieved. This is particularly a problem in cross sectional studies. In a longitudinal study we have previously made corrections of the time of first observed spermaturia to estimate the time of spermarche, calculated to be some months earlier than the first observed spermaturia. ${ }^{1} \mathrm{~A}$ similar correction has not previously been possible in cross sectional studies.

The objectives of the present study were (i) to describe the pattern of spermaturia in early and late stages of puberty and (ii) to determine the occurrence of false negative samples and their relation to age and sex characteristics, thus simplifying the estimation of the age of spermarche in future cross sectional studies.

\section{Subjects and methods}

SUBJECTS

All boys from four classes of seventh grade (age 13-14 years) and five classes of ninth or tenth grade (age 15-17 years) of two municipal schools in Copenhagen were asked to participate. Of 85 boys asked, 19 agreed to deliver urine samples. The following criteria of exclusion were applied: (a) acute diseases within the last two weeks before and during the observation period; (b) chronic disease; (c) previous orchitis; (d) varicocele; (e) enuresis; and (f) any testis $<4 \mathrm{ml}$. Only one boy was excluded, because of a testicular size less than $4 \mathrm{ml}$. Urine was thus collected from 18 healthy normal boys.

\section{METHODS}

All boys were examined by the same investigator. Genital and pubic hair stage were classified according to Tanner. ${ }^{11}$ Testicular volume was assessed with the orchidometer of Prader. ${ }^{12}$ Axillary hair stage was recorded. For nine consecutive days each boy collected fractionated 24 hour urine: the day sample was collected from 8 am to $8 \mathrm{pm}$ and the night sample from $8 \mathrm{pm}$ to $8 \mathrm{am}$, including the first morning void. Plastic containers $(2.51)$ containing $500 \mathrm{mg}$ ampicillin in $5 \mathrm{ml}$ water were provided for urine collection. The samples were thoroughly mixed and $200 \mathrm{ml}$ analysed. A method for detecting spermatozoa in urine has been reported by Baldwin ${ }^{7}$ and modified by Richardson and Short. ${ }^{6}$ With minor changes this method was applied in our study. In brief, the principle was two centrifugations, reducing the volume and concentrating the precipitate, which was examined by microscopy. Thirty high power fields $(\times 400)$ were examined by phase contrast microscopy in each of two drops of precipitate. Forty high power fields $(\times 250)$ were examined by light microscopy in each of two 
Papanicolaou stained smears. If spermatozoa were seen, the urine sample was considered to be positive. The sensitivity of the method has not been evaluated.

\section{ETHICS}

All boys and their parents gave informed consent for participation in the study. The procedures followed were in accordance with the revised Helsinki Declaration of 1983. The study was accepted by the local ethical committee.

\section{STATISTICS}

Analysis of the dependence between the results of successive observations from each boy was performed using a runs test. ${ }^{13}$ This test is based on a Markov model assumption of order 1 , specifying that the occurrence of a sperm positive sample depends on the occurrence of spermatozoa in the previous sample. The test

Table 1 Basic characteristics of the boys

\begin{tabular}{|c|c|c|c|c|c|}
\hline $\begin{array}{l}\text { Boy } \\
\text { No }\end{array}$ & $\begin{array}{l}\text { Age } \\
\text { (years) }\end{array}$ & $\begin{array}{l}\text { Mean testis } \\
\text { volume }(\mathrm{ml})^{\dagger}\end{array}$ & $\begin{array}{l}\text { Genital } \\
\text { stage }^{\ddagger}\end{array}$ & $\begin{array}{l}\text { Pubic hair } \\
\text { stage }^{\ddagger}\end{array}$ & $\begin{array}{l}\text { Axillary } \\
\text { hair stage }\end{array}$ \\
\hline 1 & $13 \cdot 50$ & $11 \cdot 00$ & 3.0 & 3.5 & $2 \cdot 0$ \\
\hline 2 & 14.00 & 15.00 & 3.0 & 3.0 & $1 \cdot 0$ \\
\hline 3 & 13.50 & $9 \cdot 00$ & $2 \cdot 0$ & 1.5 & $1 \cdot 0$ \\
\hline 4 & $14 \cdot 25$ & $13 \cdot 50$ & $4 \cdot 0$ & $4 \cdot 0$ & 1.0 \\
\hline 5 & $13 \cdot 25$ & 8.00 & $2 \cdot 0$ & 1.0 & 1.0 \\
\hline 6 & 13.75 & $17 \cdot 50$ & $4 \cdot 0$ & 4.0 & 2.0 \\
\hline 7 & 13.25 & 11.00 & 3.0 & 3.0 & $2 \cdot 0$ \\
\hline 8 & 14.00 & 8.00 & $2 \cdot 5$ & 2.5 & $2 \cdot 0$ \\
\hline 9 & 16.00 & $20 \cdot 00$ & $5 \cdot 0$ & $5 \cdot 0$ & $2 \cdot 5$ \\
\hline 10 & $15 \cdot 25$ & $16 \cdot 25$ & $5 \cdot 0$ & $5 \cdot 0$ & 3.0 \\
\hline 11 & 15.50 & 25.00 & $5 \cdot 0$ & $5 \cdot 0$ & 3.0 \\
\hline 12 & 16.00 & 25.00 & $5 \cdot 0$ & $5 \cdot 0$ & 3.0 \\
\hline 13 & $15 \cdot 75$ & $18 \cdot 75$ & $4 \cdot 5$ & 4.5 & $2 \cdot 0$ \\
\hline 14 & 16.00 & 15.00 & $4 \cdot 5$ & $4 \cdot 5$ & 3.0 \\
\hline 15 & $17 \cdot 25$ & 25.00 & $5 \cdot 0$ & $5 \cdot 0$ & 3.0 \\
\hline 16 & 16.75 & $20 \cdot 00$ & $4 \cdot 5$ & $4 \cdot 5$ & 3.0 \\
\hline 17 & $16 \cdot 25$ & $20 \cdot 00$ & $4 \cdot 0$ & $4 \cdot 0$ & $2 \cdot 0$ \\
\hline 18 & $16 \cdot 25$ & 15.00 & $4 \cdot 5$ & $4 \cdot 0$ & $2 \cdot 0$ \\
\hline
\end{tabular}

* Age: grouped in three month intervals.

t Mean testicular volume: right plus left testicular volumes divided by two.

₹ Genital stage and pubic hair stage: according to Tanner. ${ }^{11}$

Evaluation 4-5 is written as 4.5 .

Axillary hair stage: 1 , no hair; 2 , hair but non-adult; 3, adult type. Evaluation $2-3$ is written as 2.5 .

Table 2 Pattern of spermaturia

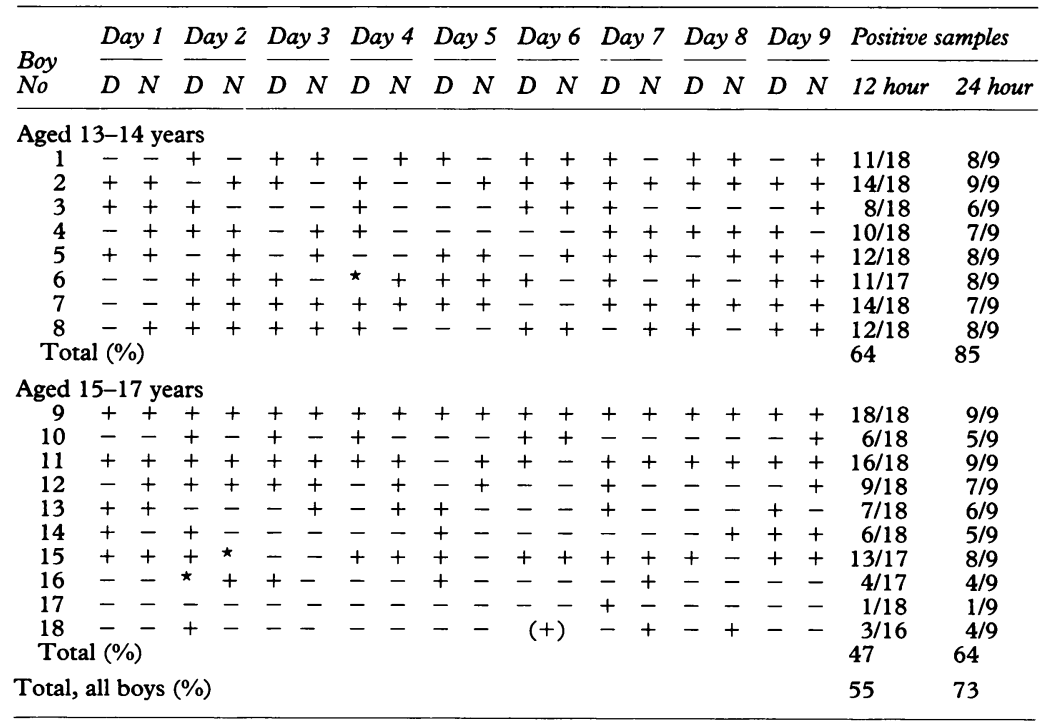

$\mathrm{D}$, day; $\mathrm{N}$, night; + , urine sample with spermatozoa; - , urine sample without spermatozoa; $\star$, missing sample; $(+)$ day and night sample mixed, with spermatozoa. for independence within this model was performed by calculating the exact $p$ value for each boy separately.

Tests for the difference in occurrence of spermaturia between night and day and between individual boys as well as tests for the interaction between boys and night/day were performed separately for each of the age groups 13-14 and 15-17 years using standard logistic regression.

Tests for relating the individual differences in the occurrence of spermaturia to age and primary and secondary sex characteristics were performed using standard logistic regression.

\section{Results}

All boys showed spermaturia at least once during the period of the study. Table 1 gives the basic characteristics of the boys and table 2 gives the pattern of spermaturia. For three boys one urine sample each was missing; two day samples and one night sample. On one occasion the day and night samples were mixed and showed spermaturia.

A total of 174 of 319 (55\%) urine samples showed spermaturia - that is, $45 \%$ of the urine samples were false negative. For the boys aged $13-14$ years $36 \%$ of the urine samples were false negative and for the boys aged 15-17 years $53 \%$ of the urine samples were false negative. The frequency of false negative samples in the individual boys varied from 0 to $94 \%$, with the boys in the group aged 15-17 years showing the greatest variation. Assuming that at least one positive 12 hour urine sample yields a positive 24 hour urine sample, $27 \%$ of the 24 hour urine samples would be false negative (table 2). For the boys aged 13-14 years $15 \%$ would be false negative, and for the boys aged 15-17 years $36 \%$ would be false negative.

There were no signs of dependence between the results of successive observations for any of the 18 boys - that is, no difference between the probabilities of spermaturia after a negative and a positive sample. In the case of missing samples only actually successive samples were compared. No significant difference in the occurrence of spermaturia between day and night samples was found $(p=0.43)$. The difference in the occurrence of spermaturia between boys was highly significant $(p<0.00001)$. Analysing each of the two age groups separately showed that the difference between boys was mainly caused by differences between the boys aged 15-17. For the eight boys aged 13-14 there was no significant difference in their individual probabilities of a sperm positive sample $(p=0.47)$, whereas the individual differences were highly significant for the 10 boys aged 15-17 ( $p<0.00001)$.

The occurrence of spermaturia for the boys aged 13-14 was significantly higher than that of the boys aged 15-17 $(p=0.003)$. The individual differences in the frequency of spermaturia could not be explained by differences in primary and secondary sex characteristics $(p<0.00001)$. This is mainly caused by the wide variation between the older, more mature boys. 


\section{Discussion}

The frequency of spermaturia was significantly higher for the more immature boys aged 13-14 years than that of the boys aged 15-17 years, who showed the widest variation. Our observation that spermaturia was a more regular event during early and mid-puberty than in older subjects is in agreement with the work of Schaefer $e t a l^{4}$ and Hirsch $e t a l^{2}$ who described an increasing occurrence of false negative urine samples with increasing age. Thus the more mature the subject is, the higher the occurrence of false negative samples tends to be and, simultaneously, the individual variation becomes wider. Considerably more urine samples are thus needed from mature than from immature boys to detect spermaturia. This must be remembered when designing cross sectional studies to determine the age of spermarche. Our inability to relate spermaturia to sex characteristics is surprising. We assumed that sex characteristics were closely related to spermaturia, but because of the wide variation between the more mature boys this relation could not be described with logistic regression. Hence any simplification of cross sectional studies based on this relation seems useless. No previous reports are available on this subject.

In adults, spermaturia is normally the result of urethral wash out after ejaculation, as it has been shown that most of the spermatozoa in a void are concentrated in the first urine fraction and sperm only appear after ejaculation. ${ }^{8}$ Spermaturia has also been described in adults during prolonged sexual abstinence, 1415 however, as well as after spontaneous nocturnal emissions ${ }^{15}$ and after retrograde ejaculation. ${ }^{8}$ The only two known studies of the onset of ejaculations in puberty found that boys were generally in middle or late puberty before they experienced their first ejaculations. ${ }^{910}$

Spermaturia in non-virilised boys is probably a result of spontaneous, continuous, or intermittent flow in contrast with the peristaltic flow in ejaculations and nocturnal emissions.

In this study $27 \%$ of the 24 hour urine samples were false negative. Table 3 gives the occurrence of false negative samples in other studies. In adults spermaturia depends strongly on the sperm count in the ejaculate and the number of urinations since the last ejaculation. ${ }^{8}$ There were no signs of dependence between the results of successive urine samples. This is in contrast with a previous study, in which a significantly higher frequency of spermaturia was found after a negative urine sample than after a positive specimen. This difference was more distinct for boys aged 12-13 years than for boys aged $15-16$ years. $^{2}$

There was no significant difference in the occurrence of spermaturia between day and night samples, which means that more information can be gained from 24 hour urine samples than from morning voids. This relation has not previously been studied.

Only 19 of $85(22 \%)$ boys agreed to participate. We believe that the reason for the low participation was that many pubertal boys found it embarrassing to carry urine containers to school. We have no reason to suspect that any selection bias has occurred, however. Sperm negative urine samples may be due to missing spermatozoa or a methodological inability to demonstrate the cells, which could result from only a few spermatozoa in the specimen, or from the destruction or disappearance of the spermatozoa in sediment before examination. Loss of urine (that is, noncompliance of the subjects) could also be the cause of false negative samples. In this study, usually only a few spermatozoa were seen.

In conclusion, we found a large variation in spermaturia between and within boys of the same stage of puberty. Spermaturia was in general a more common and regular event during early and mid-puberty than in more mature boys, however. This indicates that the mechanism of spermaturia in early and late puberty could be different, and considerably more urine samples will be needed from mature than from immature boys to detect spermaturia.

We hypothesise that spermaturia in nonvirilised boys with early growth of the testes could be a result of a spontaneous, continuous flow of spermatozoa to the urinary tract, in contrast with the peristaltic flow during ejaculation occurring at a later stage of puberty when androgen levels become high enough to allow ejaculation.

The Maternal and Child Health, WHO Task Force on Adolescent Reproductive Health are thanked for financial support. The laboratory technicians Anne Marie Ottesen, Majken Simonsen, Lisbet Cantel, and Annelise Person are Majken Simonsen, Lisbet Cantel, and An
thanked for their skilful technical assistance.

1 Nielsen CT, Skakkebæk NE, Richardson DW, et al. Onset of the release of spermatozoa (spermarche) in boys in relation to age, testicular growth, pubic hair, and height. f Clin Endocrinol Metab 1986; 62: 532-5.

Table $3 \quad$ False negative samples in other studies

\begin{tabular}{|c|c|c|c|c|c|}
\hline Design & Reference & Subjects & $\begin{array}{l}\text { No of } \\
\text { samples }\end{array}$ & $\begin{array}{l}\text { Sample } \\
\text { type }\end{array}$ & $\begin{array}{l}\text { Frequency of } \\
\text { false negative } \\
\text { samples (\%) }\end{array}$ \\
\hline $\begin{array}{l}\text { Longitudinal } \\
\text { Longitudinal } \\
\text { Cross sectional } \\
\text { Cross sectional } \\
\text { Cross sectional }\end{array}$ & $\begin{array}{l}\text { Nielsen et al }{ }^{1} \\
\text { Richardson and Short } \\
\text { Kulin et } \text { al }^{3} \\
\text { Weissenberg et } a l^{8} \\
\text { Weissenberg et al }\end{array}$ & $\begin{array}{l}33 \text { pubertal boys } \\
53 \text { pubertal boys } \\
13 \text { pubertal boys } \\
136 \text { men, sperm count }>10 \times 10^{6} \\
35 \text { men, sperm count }<10 \times 10^{6} \\
\text { and not azo-ospermic }\end{array}$ & $\begin{array}{r}329 \\
140 \\
130 \\
136 \\
35\end{array}$ & $\begin{array}{l}24 \text { hour } \\
\text { Morning voids } \\
\text { Morning voids } \\
\text { Postejaculatory } \\
\text { Postejaculatory }\end{array}$ & $\begin{array}{r}53 \\
38 \\
75 \\
9 \\
40\end{array}$ \\
\hline $\begin{array}{l}\text { Cross sectional } \\
\text { Cross sectional } \\
\text { Cross sectional }\end{array}$ & $\begin{array}{l}\text { Freund and Peterson }(1975)^{\star} \\
\text { Johnson } \\
\text { Wilhelm and Seligmann }^{15}\end{array}$ & $\begin{array}{l}10 \text { men } \\
\text { Nine men ejaculating daily } \\
\text { Two men, prolonged sexual rest }\end{array}$ & $\begin{array}{r}60 \\
9 \\
78\end{array}$ & $\begin{array}{l}24 \text { hour } \\
24 \text { hour } \\
\text { Morning or } \\
\text { evening voids }\end{array}$ & $\begin{array}{l}57 \\
67 \\
26\end{array}$ \\
\hline
\end{tabular}

* Abstract: Freund M, Peterson RN. Sperm in the urine of man. Abstract presented at the 59th annual meeting of Federation of American Societies for Experimental Biology, Atlantic City, New Jersey, 13-18 April, 1975 (Fed Proc 1975; 34: 255). 
2 Hirsch M, Shemesh J, Modan M, Lunenfeld B. Emission of spermatozoa, age of onset. Int f Androl 1979; 2: 289-98. Kulin HE, Frontera MA, Demers LM, Bartholomew MJ, Lloyd TA. The onset of sperm production in pubertal boys. Relationship to gonadotropin excretion. $\mathrm{Am} \mathcal{F} \mathrm{Dis}$ Child 1989; 143: 190-3.

4 Schaefer F, Marr J, Seidel C, Tilgen W, Scharer K. Assessment of gonadal maturation by evaluation of spermaturia. Arch Dis Child 1990; 65: 1205-7.

5 Hirsch M, Lunenfeld B, Modan M, Ovadia J, Shemesh J. Spermarche - the age of onset of sperm emission. $\dot{f}$ Adolesc Health Care 1985; 5: 35-9.

6 Richardson DW, Short RV. Time of onset of sperm production in boys. $\mathcal{f}$ Biosoc Sci Suppl 1978; 5: 15-25.

7 Baldwin BT. The determination of sex maturation in boys by a laboratory method. $f$ Comp Psychol 1928; 8: 39-43.
8 Weissenberg $R$, Rozenman $H$, Hova $M$, Modan $M$, Lunenfeld $\mathbf{B}$. The diagnostic value of sperm in postLunenfeld $B$. The diagnostic value of sperm
ejaculatory urine. Int $\mathcal{f}$ Androl $1984 ; 7: 142-8$.

9 Carlier JG, Steeno OP. Oigarche: the age at first ejaculation. Andrologia 1985; 17: 104-6.

10 Laron Z, Arad J, Gurewitz R, Grunebaum M, Dickerman $Z$. Age at first conscious ejaculation: a milestone in male puberty. Helvetica Paediatrica Acta 1980; 35: 13-20.

11 Tanner JM. Growth at adolescence. Oxford: Blackwell, 1962.

12 Prader A. Testicular size: assessment and clinical importance. Triangle 1966; 7: 240-3.

13 Mood AM. The distribution theory of run's. Annals of Mathematical Statistics 1940; 11: 367-92.

14 Johnson L. A re-evaluation of daily sperm output of men. Fertil Steril 1982; 37: 811-6.

15 Wilhelm SF, Seligmann AW. Spermatozoa in urine. $A m \mathcal{F}$ Surg 1937; 35: 572-4.

\section{Newborns find too much prostaglandin hard to stomach}

Infusion of prostaglandin $\mathrm{E}_{1}$, in newborn babies to keep the ductus arteriosus open in congenital heart disease, or to treat persistent fetal circulation or pulmonary hypertension, may cause gastric antral obstruction. Workers in Toronto (Nathan Peled and colleagues, New England fournal of Medicine 1992; 327: 505-10) noticed antral mucosal thickening in two term babies, one with a hypoplastic left ventricle and pulmonary valvular dysplasia and one with pulmonary hypertension. They therefore reviewed the notes of all neonates treated with prostaglandin $\mathrm{E}_{1}$ at the Hospital for Sick Children, Toronto over a two year period beginning on 1 October 1989. Of the 74 babies in the study five were shown to have antral mucosal hyperplasia either on ultrasound scan $(n=3)$, at necropsy $(n=1)$, or by both ultrasound and necropsy $(n=1)$. Four other babies had clinical features suggesting antral obstruction but no ultrasound or necropsy confirmation of antral hyperplasia. The five babies with proved antral hyperplasia were slightly less mature than the other $69(37 \cdot 4$ weeks $v 39.4$ weeks; $\mathrm{p}<0.01$ ) but the most striking finding was that they had been given more prostaglandin. The babies with no evidence of gastric obstruction $(n=65)$ had received a total mean (SD) cumulative dose of 279 (270) $\mu \mathrm{g} / \mathrm{kg}$ of body weight. The four babies with clinical signs only had had $528(306) \mu \mathrm{g} / \mathrm{kg}$ and the five with proved antral hyperplasia had had $2982(1392) \mu \mathrm{g} / \mathrm{kg}(\mathrm{p}<0.001$ for comparison with the first group and $<0.01$ for comparison with the second). The total duration of infusion was 54 (58) hours in the 'normal stomach' group, $119(60)$ hours in the 'clinical obstruction' group, and 569 (341) in the 'proved atrial hyperplasia' group $(p<0.001$ for comparison of the third with the first group and $<0.05$ for comparison of the third with the second group).

Could the antral mucosal hyperplasia be a consequence of the more severe disease in the babies who needed prostaglandin for longer? That seems unlikely because such changes are not described in chronic hypoxia alone and similar changes have been observed in normal adults given prostaglandin $\mathrm{E}_{2}$ orally. Moreover, two babies in the Toronto series showed regression of the antral hyperplasia after stopping the infusion. The authors conclude that babies given prostaglandin $E_{1}$ at a dose of $0.05 \mu \mathrm{g} / \mathrm{kg}$ of body weight per minute for more than five days should be monitored for evidence of antral obstruction. Nasojejunal feeding may get round the problem but one baby who died had pathology in the duodenum that showed thinning of its muscle layer and was grossly distended with mucus. How many neonatologists will be confident of making an ultrasound diagnosis of atrial mucosal hyperplasia? The cut off point at five days seems arbitrary. It is not clear whether the figures quoted for duration and cumulative dose refer to total dosage or to the dose given when signs of antral obstruction first appeared. The lowest cumulative dose associated with clinical features of gastric obstruction was $222 \mu \mathrm{g} / \mathrm{kg}$ and with antral hyperplasia, 1560 $\mu \mathrm{g} / \mathrm{kg}$. At a rate of $0.05 \mu \mathrm{g} / \mathrm{kg}$ per minute these doses would be given in 74 and 520 hours. Clearly any baby who fails to 'retain' feeds while being treated with prostaglandin will be suspected of developing this complication. 